2016-11-02

\title{
Evaluating your professionalism
}

\author{
Burr, Steven
}

http://hdl.handle.net/10026.1/9318

10.12968/hmed.2016.77.11.634

British Journal of Hospital Medicine

Mark Allen Group

All content in PEARL is protected by copyright law. Author manuscripts are made available in accordance with publisher policies. Please cite only the published version using the details provided on the item record or document. In the absence of an open licence (e.g. Creative Commons), permissions for further reuse of content should be sought from the publisher or author. 


\title{
Author's final draft of an article published in BJHM, 2016
}

\section{Evaluating your professionalism}

\author{
Burr SA, Neve H \& Leung YL
}

What does being professional look like? Does professionalism mean that you do the 'righteorrect' thing, even when no-one is looking? How do you evaluate your professionalism knowledge, values and behaviour? How do you ensure you have the confidence to identify and address underperformance in professionalism? How do you ensure you are capable and can transfer your professionalism to different circumstances?

\section{HOW PROFESSIONALISM CHANGES}

The term 'professional' derives from the notion of an occupation or vocation that one 'professes' to be capable in as well as "a vocation with a body of knowledge and skills (expertise) put into service for the good of others; the welfare of society", but has also become associated with meeting the standards required of a statutory regulatory body. There are numerous definitions of professionalism, reflecting its multidimensional and complex nature. It has been What constitutes professional competence has been explicitly defined relatively recently as "the habitual and judicious use of communication, knowledge, technical skills, clinical reasoning, emotions, values, and reflection in daily practice for the benefit of the individual and community being served." (Epstein \& Hundert, 2002). However, hiding behind the label "I'm just a professional doing a job" is itself unprofessional. Increasingly professionalism is associated with individual's evolving 'professional identity', the beliefs and values that underpin how individuals define and view themselves as a professional (Cruess et al, 2015). However Furthermore, professionalism has also been described as a continuum, extending beyond the individual to include interpersonal and societal elements, including interactions with others, social responsibility and morality (Hodges et al 2010). It can also include a requirement to work collectively as a profession to debate, establish and enforce standards (Wynia et al 2014).

What is clear is that you cannot describe yourself as being professional, as that is determined by the perceptions that others have of you (Maister, 2000). Thus hiding behind the label "I'm justa prossional doing a job" is itself unprofessional. It is not professional to hide behind a claim of being a professional in order to excuse an inappropriate action or inaction. The quintessential professional used to be a white man in a suit and tie, with a congenial smile and an authoritarian paternalistic style. Clearly the concept of what qualifies has changed, and is determined by norms which change over time (Hilton \& Southgate, 2007; van Mook et al 2009a ) 2014). Within clinical practice there has been a shift from paternalism to co-construction: through psychological, social, cultural, and political processes. Being professional is not the job you do or what you look like, it's how you do the job and how you are perceived by others. Furthermore what, and the behaviour that is required of you can be expected to change. Being Pprofessional behaviour does not depend on being a qualified member of a regulated profession (although retaining professional registration does depend on being professionalbehaviour). Indeed people don't not need to belong to an established profession to hold professional values and have a professional 
work ethic. Thus within medicine it is not enough to be qualified, registered and keep up-to-date with General Medical Council guidelines (General Medical Council, 2013); it is also important to continuously develop your own professional identity andby ensureing that your practice complies with the expectations of others.

\section{PROFESSIONAL ATTRIBUTES}

When observing others do you recognise professionalism when you see it? Is it easier to recognise unprofessional behaviour? People expect a professional to act as their advocate. They need to know that you share the same goals, care about what is important to them, and will always strive to serve their best interests - to the best of your ability - whatever the circumstances. Thus doing the correct 'right' thing is about being considerate of others.

There are many lists of qualities associated with being professional (Wynia et al., 2014; Table 1). Key attributes which feature include: exhibiting ethical principles, integrity, being reliable and responsive. It is essential to have effective interactions with staff and patients, and with any other people who are important to patients. It is also necessary to demonstrate insight into your own health (Wilkinson et al., 2009) and self-regulate your availability to others whenever your ability to take professional responsibility may be compromised. To maximise success you need to reflect on practice and be committed to improvement of competence in yourself, others, and systems.

\section{Table 1. Qualities associated with professionalism}

Considerate of others and assertively manages risk to act in their best interests

Appropriatefonsistent ethical conduct in different situations

Interacts and engages effectively with colleagues, patients and otherseffectively with others; being engaged, with appropriate etiquette

Honest, trustworthy and keeps their word; being dependable

Does not use good behaviour to justify bad behaviour

Has insight into their own health and can appropriately regulate their availability to others

Mindful, emotionally controlled and resilient

Reflects on practice, acts on constructive criticism, and committed to autonomous improvement

Ability to work with uncertainty and complexity and adapt their professionalism as needed

\section{AIMS OF PROFESSIONALISM}

Firstly, there is a need to ensure minimum standards for registration and revalidation (General Medical Council, 2012). Secondly, assessment of professionalism is important asuring in order to identify gaps and lapses, and direct to remediation as appropriate. Finally, assessment Assessment or 'meAleasurement is difficult rimarilybecause of the different elements of 
professionalism, the different methods required, and the consequent tension between identifying minimum competence (to ensure safety), promoting high levels of capability (Neve \& Hanks, in press) and ranking (to encourage development; Archer et al., 2015).

\section{HOW CAN PROFESSIONALISM BE MEASURED?}

With a wide variety of key attributes, it is clear that multiple methods of measurement are required (Hawkins et al., 2009; Hodges et al., 2010; Lockyer, 2013). Each attribute needs clear criteria for making judgements at the boundaries of unsatisfactory and excellent performance. If gradations or degrees of transgression can be identified then the attribute can be measured on a scale and benchmarked. High and low standards need to be qualified, with descriptive criteria to aid judgements. Furthermore events need to be triangulated (i.e. transgressions corroborated by multiple sources or independent incidents)triangulation and have the scope to accumulate over time, asto-provide evidence relevant to practice (van Mook et al., 2009a-g). Each event should have an associated record of its magnitude and frequency; supported by the individual's rationale for their action(s), along with the total volume of uneventful equivalent professional interactions. This enables the number of transgressions to be expressed against the number of opportunities within a similar context when such a transgression could have occurred but didn't (e.g. 3 formal complaints of being rude in an outpatient clinic from 3 separate patients spread over 6 years against a background of 9000 outpatient appointments over that period without any other problem on record). The incidence of adverse events enables comparison with professional norms, but records of good behaviour should not be used to negate or justify bad behaviour. There must be transparent links to 'Fitness to Practice' procedures as appropriate (General Medical Council, 2014). Measurement should be 'unscheduled' as well as 'scheduled', with a formative opportunity before the first summative measurement, be it by staff in different categories, peers and self, as well as senior staff and patients (Ginsberg et al., 2000), and above all be longitudinal (Goldie, 2013).

Professionalism is very hard to assess well, particularly in complex real world settings, and there is no gold standard. There is evidence for dozens of different tools which can be used to assess professionalism (Wilkinson et al., 2009). Most tools rely on observable behaviours (Rodriguez et al., 2012), and it has long been recognised that there is not much evidence supporting their interpretation (Ginsberg et al., 2004; Lynch et al., 2004), although a framework has more recently been developed to establish validity (Holtman, 2008; Clauser et al., 2012). Values and behaviour differentiate between thinking and doing; and values can be mimicked by changing behaviour to conform to expected norms. Often there is only evidence of transgression in the form of a subjective view from a single individual, lacking independent corroboration. Integrating professionalism with measures of other aspects of practice provides a more holistic assessment, but single incidents can then influence multiple decisions about an individual's wider performance (i.e. risking double jeopardy). Particular aspects which are of repeated concern are failure to accept constructive criticism and unreliable attendance (Papadakis et al., 2005), suggesting a lack of ownership and insight into their problem.

Assessing professionalism implies quantification. Yet reducing professionalism to numbers may not reflect "the richness of real-life clinical medicine" and such assessments risk being invalid (Amin, 2012). Assessors should be well trained but may need some freedom to use their judgment where 
assessing hard to define behaviours. If professionalism is quantified then it will result in the ranking of individuals; this promotes competition whichand could undermine teamwork. One way of fo overcominge this would be to,-staff could assess the performance of a team as a whole. This would reflect the real world where the quality of care is often more dependent on a team than on an individual. As part of this staff could rate how each member (including themselves) hasthe contributed to the teamion of each member in their team (including themselves) to facilitating the profsional performance of their team as a order to maximise the success of one's individual contribution within a multi-disciplinary team it is therefore important to know not only the professional governance arrangements of the relevant allied professions but also their skills, experience and expectations.

\section{CAN PROFESSIONALISM BE TAUGHT AND LEARNT?}

Are bad people born bad? Will bad people will always be bad? Do prospective professionals all begin their training with the same level of professionalism? If the answer to these questions is no, then clearly professionalism is not innate but a product of experiential conditioning. Different backgrounds and ethnographic norms give rise to different starting points. As such, deficits can be identified and improved upon.

\section{HOW CAN PROFESSIONALISM BE IMPROVED?}

Strategies to improve professionalism require knowledge of expected norms, along with explanation to convey understanding of the reasons for the requirements so as to improve engagement (e.g. relating to boundaries between personal and professional life; Lapid et al., 2009 and formal versus informal encounters; Monrouxe \& Rees, 2012). Exposure to role models, 360 degree feedback, and significant formative experiences can be transformational (Pearson \& Hoagland, 2010; Stupans et al., 2011; Wilson et al., 2013), particularly where opportunities are provided to promote reflection on these (Mann 2009). Reflective practice, alone and in groups, should be encouraged and can be improved through providing facilitation and feedback on an induas (Camp et al., 2010), and facilitating group review of dilemmas (Bernabeo et al., 2013). Poorer reflective practice correlates with poorer peer ratings (Wittich et al., 2013). Beingłt is important to be non-judgementally receptive to feedback is in itself an element of professionalism; learning from the perceptions of others is an important way of to increasinge what we know about ourselves by learning from the perceptions of others (Luft \& Ingham, 1955). Core values cannot't easily be changed without providing exposureexperiences to develop sympathy \&and where reasonable empathy (Table 2). Exposure to transformational experiences (e.g. altruism, birth, death, deprivation, discrimination, pain, success/failure, mistakes, stoicism, revelatory feedback) can occur in different combinations, orders, magnitudes, time intervals and states of receptiveness; and thus may have different impacts and be assimilated into values to varying degrees. Motivation to develop can also be provided by monitoring (General Medical Council, 2012) and knowledge of the regulatory 'Fitness to Practice' sanctions (General Medical Council, 2015). However it is important not to rely on the threat of punishment to ensure conformity, but to use praise more than penalties wherever possible to encourage development (O'Sullivan et al., 2012).

Table 2. Experiences which could transform core values and differences in their context 


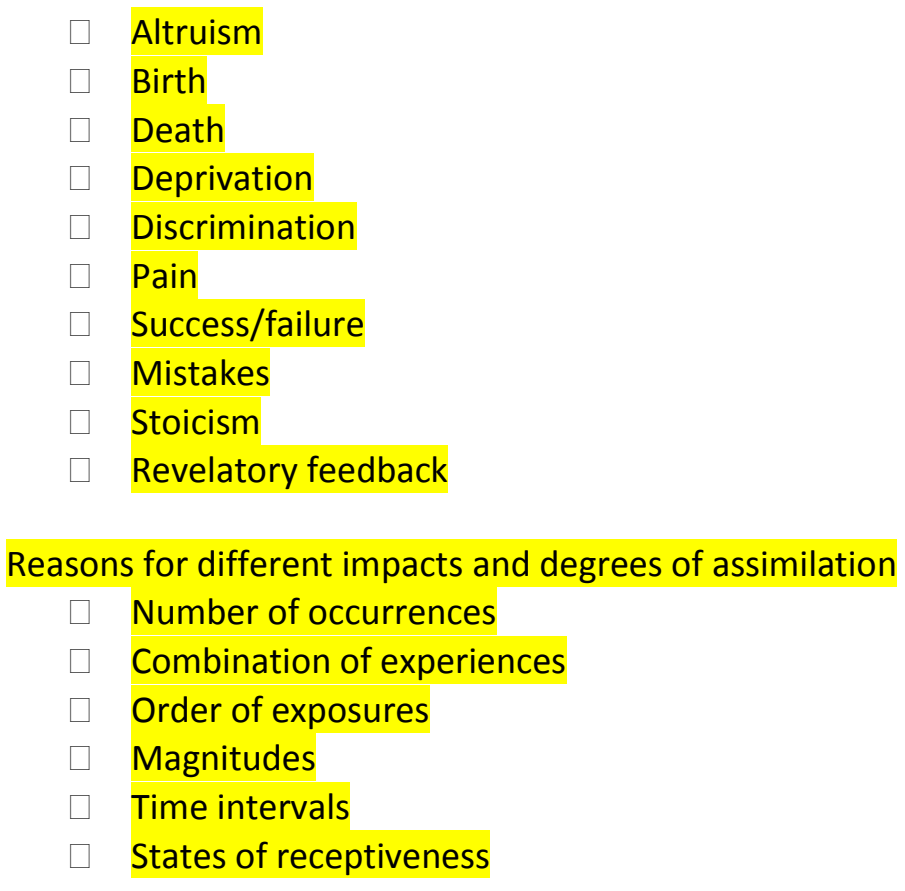

\section{FACTORS AFFECTING PROFESSIONALISM JUDGEMENTS}

We all undertake different journeys of professionalism from novice, through competency and proficiency, to expert (Dreyfus, 2004). Professionalism excellence depends more on flexibility, motivation and social competence than technical expertise (Lindberg \& Rantatalo, 2014).

Professional capability ensures the transfer and integration of appropriate behaviours between different settings. To assess this there needs to be empathy for the context, conflicting demands and stressors (Ginsberg et al., 2000; Holtman, 2008). The appropriateness of any given professional decision and action will depend on the circumstances of all concerned. There may be associated mitigating factors which require discretion to determine whether an incident is an isolated lapse or a pattern of persistent misconduct which brings the profession into disrepute. Training of assessors is vital. To ensure that longitudinal records are unbiasedresentivit is important to ensure wherever possible that knowledge of existing transgressions does not influence the reporting of new events. Different perspectives (e.g. peers and other grades of own profession, individuals from other professional and staff groups, patients and other members of the public) can also be useful in determining the significance of events. Individualsother individuals-may have differentan

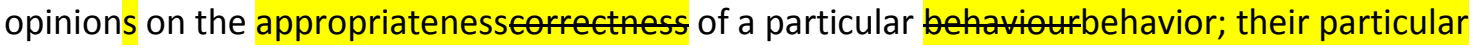
perspective may be influenced by, but from their own perspective, with status, stakes, support availability, time-pressures and ethnographies differ for them.

Principles common to other regulated professions include etiquette, safety, reliability, engagement, self-improvement and risk management, for example by pilots (Birden et al., 2013) and the police (College of Policing, 2014). Successful risk taking needs to be identified and shared (College of Policing, 2013). When managing uncertainty, excessive penalisation of mistakes leads to risk aversion and delayed action as the default decision. Hesitation is associated with its own dangers. Nevertheless it is important not to trust your intuition unconditionally (Kahneman, 2011). Intuition can be accentuated by emotions (Leffel et al., 2015), and this should be reflected upon. It is important to recognise gut feelings, and challenge yourself to think critically about why you might be 
experiencing them. Always try to be mindful of your own unconscious confirmation bias, and look for objective evidence on which to base decisions (Leung et al., 2011). To overcome inertia it is necessary to decide what action to take based on the evidence available in that moment, in order to protect and help others, without being influenced by personal self-interest.

\section{KEY POINTS}

Professionalism is a norm referenced construct, which changes over time and context

Doing the correctright thing is about being considerate of others

Evaluation requires triangulation from multiple sources at multiple times

Misconduct depends on magnitude, frequency and volume; as perceived by others

Deficits can be identified and improved upon

Changing values depends on receptiveness to transformational experiences

Behaviour can be influenced by context and perceived risks

It is vital to promote high standards of professionalism, not just ensure minimum standards

It is important to remain calm, consistent and acton evidence

\section{REFERENCES}

Amin Z. (2012) Purposeful assessment. Medical Education 46(1): 4-7

Archer J, Regan de Bere S, Nunn S, et al (2015) No one has yet properly articulated what we are trying to achieve: a discourse analysis of interviews with revalidation policy leaders in the United Kingdom. Acad Med 90(1): 88-93

Bernabeo EC, Holmboe ES, Ross K et al (2013) The utility of vignettes to stimulate reflection on professionalism: theory and practice. Adv in Health Sci Educ 18:463-484 (doi: 10.1007/s10459-0129384-x)

Birden H, Glass N, Wilson I, et al (2013) Teaching professionalism in medical education: a best evidence medical education (BEME) systematic review. BEME Guide No.25. Med Teach 35: 12521266

Camp CL, Gregory JK, Lachman N et al (2010) Comparative Efficacy of Group and Individual Feedback in Gross Anatomy for Promoting Medical Student Professionalism. Anat Sci Educ 3(2): 64-72

Clauser BE, Margolis MJ, Holtman MC et al (2012) Validity considerations in the assessment of professionalism. Adv in Health Sci Educ 17: 165-181 (doi: 10.1007/s10459-010-9219-6)

College of Policing (2013) Risk. https://www.app.college.police.uk/app-content/risk-2/risk/ Accessed 20 January 2016. 
College of Policing (2014) Code of ethics: A Code of Practice for the Principles and Standards of Professional Behaviour for the Policing Profession of England and Wales. College of Policing Limited, Coventry: 1-34

Cruess RL, Cruess SR, Boudreau JD et al (2015) A schematic representation of the professional identity formation and socialization of medical students and residents: A guide for medical educators. Academic Medicine 90(6): 718-725

Dreyfus SE (2004) The five-stage model of adult skill acquisition. Bulletin of Science, Technology and Society 24: 177-181

Epstein RM, Hundert EM (2002) Defining and assessing professional competence. JAMA 287(2): 226235

General Medical Council (2012) Supporting information for appraisal and revalidation. General Medical Council, London: 1-16

General Medical Council (2013) Good medical practice. General Medical Council, London: 1-36 General Medical Council (2014) The meaning of fitness to practice. General Medical Council, London: 1-3

General Medical Council (2015) Sanctions guidance. General Medical Council, London: 1-41

Ginsburg S, Regehr G, Lingard L (2004) Basing the evaluation of professionalism on observable behaviors: a cautionary tale. Acad Med 79(10): S1-S4

Goldie J (2013) Assessment of professionalism: A consolidation of current thinking. Med Teach 35: e952-e956 (dx.doi.org/10.3109/0142159X.2012.714888)

Hawkins RE, Katsufrakis PJ, Holtman MC, Clauser BE (2009) Assessment of medical professionalism: Who, what, when, where, how, and ... why? Med Teach 31: 348-361 (dx.doi.org/10.1080/01421590902887404)

Hilton S, Southgate L (2007) Professionalism in medical education. Teaching and Teacher Education 23: 265-279 (doi:10.1016/j.tate.2006.12.024)

Hodges B, Ginsburg S, Cruess R, et al (2011) Assessment of professionalism: recommendations from the Ottawa 2010 Conference. Med Teach 33: 354-63 (dx.doi.org/10.3109/0142159X.2011.577300) Lapid M, Moutier C, Dunn L et al (2009) Professionalism and Ethics Education on Relationships and Boundaries: Psychiatric Residents' Training Preferences. Academic Psychiatry 33(6): 461-469

Leffel GM, Oakes Mueller RA, Curlin FA, Yoon JD (2015) Relevance of the rationalist-intuitionist debate for ethics and professionalism in medical education. Adv in Health Sci Educ 20: 1371-1383 (doi: 10.1007/s10459-014-9563-z)

Leung YL, Adesara S, Burr SA (2011) Learning to make better clinical decisions. Br J Hosp Med 72(11): 642-5 (doi: 10.12968/hmed.2011.72.11.642) 
Lindberg O, Rantatalo O (2014) Competence in professional practice: A practice theory analysis of police and doctors. Human Relations 1-22 (doi: 10.1177/0018726714532666)

Lockyer J (2013) Multisource Feedback: Can It Meet Criteria for Good Assessment? Journal of Continuing Education in the Health Professions 33(2): 89-98 (doi: 10.1002/chp)

Luft J, Ingham H (1955) The Johari window, a graphic model of interpersonal awareness. Proceedings of the western training laboratory in group development. University of California, Los Angeles

Lynch DC, Surdyk PM, Eiser AR (2004) Assessing professionalism: a review of the literature. Med Teach 26(4) :366-373 (dx.doi.org/10.1080/01421590410001696434)

Maister DH (2000) True Professionalism: The Courage to Care about Your People, Your Clients, and Your Career. Free Press, New York: 210

Mann K, Gordon J, MacLeod A (2009) Reflection and reflective practice in health professions education: a systematic review. Advances in Health Sciences Education 14(4): 595-621

Neve H, Hanks S “When I say...capability." Medical Education, In Press

O'Sullivan H, van Mook W, Fewtrell R, Wass V (2012) Integrating professionalism into the curriculum: AMEE Guide No. 61. Med Teach 34: e64-e77 (dx.doi.org/10.3109/0142159X.2012.655610)

Papadakis M, Teherani A, Banach M, et al (2005) Disciplinary action by medical boards and prior behavior in medical school. N Engl J Med 353: 2673-2682

Rodriguez E, Siegelman J, Leone K, Kessler C (2012) Assessing Professionalism: Summary of the Working Group on Assessment of Observable Learner Performance. Acad Emerg Med 19(12): 13721378 (doi: 10.1111/acem.12031)

Stupans I, Scutter S, Sawyer T (2011) Fostering professionalism through scaffolding in first year clinical Placements. Innovations in Education and Teaching International 48(3): 263-274 (doi: 10.1080/14703297.2011.593703)

van Mook W, de Grave W, Wass V, et al (2009a) Professionalism: Evolution of the concept. Eur J Int Med 20: e81-e84

van Mook W, van Luijk SJ, O'Sullivan HM, et al CPM (2009b) The concepts of professionalism and professional behaviour: Conflicts in both definition and learning outcomes. Eur J Int Med 20: e85e89 (doi: 10.1016/j.ejim.2008.10.006)

van Mook W, van Luijk SJ, O'Sullivan HM, et al (2009c) General considerations regarding assessment of professional behaviour. Eur J Int Med 2009, 20: e90-e95

van Mook W, de Grave WS, van Luijk SJ, et al (2009d) Training and learning professionalism in the medical school curriculum: Current considerations. Eur J Int Med 20: e96-e100 (doi:

10.1016/j.ejim.2008.12.006)

van Mook W, Scheltus J, van Luijk SJ, et al (2009e) Teaching and learning professional behaviour in practice. Eur J Int Med 20: e105-e111 
van Mook W, Gorter SL, O'Sullivan HM, et al (2009f) Professionalism beyond medical school: An educational continuum? Eur J Int Med 20: e148-e152

van Mook W, Gorter SL, O'Sullivan HM, et al (2009g) Approaches to professional behaviour assessment: Tools in the professionalism toolbox. Eur J Int Med 20: e153-e158 (doi:

10.1016/j.ejim.2009.07.012)

Wilkinson T, Wade W, Knock L (2009) A blueprint to assess professionalism: results of a systematic review. Acad Med 84: 551-558.

Wilson A, Åkerlind G, Walsh B, et al (2013) Making 'professionalism' meaningful to students in higher education. Studies in Higher Education 38(8): 1222-1238

(dx.doi.org/10.1080/03075079.2013.833035)

Wittich CM, Pawlina W, Drake RL, et al (2013) Validation of a Method for Measuring Medical Students' Critical Reflections on Professionalism in Gross Anatomy. Anat Sci Educ 6(4): 232-238

Wynia MK, Papadakis MA, Sullivan WM, Hafferty FW (2014) More than a list of values and desired behaviors: a foundational understanding of medical professionalism. Acad Med 89(5): 712-4 (doi: 10.1097/ACM.0000000000000212) 